\title{
Bullying and cyberbullying studies in the school-aged population on the island of Ireland: A meta-analysis
}

\author{
Mairéad Foody '*, Muthanna Samara ${ }^{2}$ and James O'Higgins Norman' \\ 'Anti-Bullying Research and Resource Centre (ABC), Dublin City University, Ireland \\ ${ }^{2}$ Department of Psychology, Kingston University London, Kingston upon Thames, UK
}

Background. Bullying research has gained a substantial amount of interest in recent years because of the implications for child and adolescent development.

Aim and sample. We conducted a meta-analysis of traditional and cyberbullying studies in the Republic and North of Ireland to gain an understanding of prevalence rates and associated issues (particularly psychological correlates and intervention strategies) among young people (primary and secondary school students).

Method. Four electronic databases were searched (PsychArticles, ERIC, PsychInfo and Education Research Complete) for studies of traditional bullying and cyberbullying behaviours (perpetrators, victims or both) published between January 1997 and April 2016.

Results. A final sample of 39 articles fit our selection criteria. CMA software was used to estimate a pooled prevalence rate for traditional/cyberbullying victimization and perpetration. A systematic review on the psychological impacts for all types of bullying and previously used interventions in an Irish setting is also provided.

Conclusions. The results demonstrate the influence moderating factors (e.g., assessment tools, answer scale, time frame) have on reported prevalence rates. These results are discussed in light of current studies, and points for future research are considered.

Bullying research has gained a substantial amount of interest in recent years because of the implications for child and adolescent development. The earliest definition of bullying was provided by Olweus (1991) who described it as occurring when an individual is repeatedly exposed to intentional negative actions by another person(s), creating an imbalance in power between the perpetrator and victim. In general, the literature points to four facets of traditional (face-to-face) bullying behaviour: intentionality, repetitiveness, involving a power imbalance, and causing negative effects (Smith, 2014). It can be subdivided into specific behaviours including physical (e.g., kicking), verbal (e.g., saying hurtful things), relational (e.g., gossiping), and cyberbullying (e.g., posting negative comments about a person online).

Indeed, there has been an explosion of research in recent years into cyberbullying in particular. It is defined by Smith, Mahdavi, et al. (2008) as 'an aggressive, intentional act carried out by a group or individual, using mobile phones or the internet, repeatedly and

*Correspondence should be addressed to Mairéad Foody, Anti-Bullying Research and Resource Centre (ABC), St. Patricks Campus, Dublin City University, Drumcondra, Dublin 9, Ireland (email: Mairead.Foody@dcu.ie). 
over time against a victim who cannot easily defend him or herself' (p. 376). Although the definition of cyberbullying incorporates similar elements to traditional bullying (i.e., intentionality, power imbalance, and negative effects), there are several factors that distinguish the two. The most obvious of these is the anonymity that can be attached to a cyberbullying incident and one could argue that this might increase the power hierarchy between the perpetrator and the victim (Sticca \& Perren, 2013). Another significant difference is the large audience that a cyberbullying incident can reach, which could increase the impact the incident has on the victim's life (Grigg, 2010).

Regardless of the methods used, research has demonstrated a significant link between bullying experiences in childhood and adolescence and the subsequent social and emotional development of those involved. For example, exposure to peer victimization has been linked to anxiety, depression, low self-esteem, psychosis, and even suicide across all age groups (Wolke, Copeland, Angold, \& Costello, 2013). In addition, other factors such as lower academic achievement and early school leaving are demonstrated outcomes of bullying experiences (Cornell, Gregory, Huang, Xitao, \& Graesser, 2013; Hammig \& Jozkowski, 2013).

Despite the wealth of international research, bullying and its effects are relatively under-researched in schools across Northern Ireland and the Republic of Ireland. To date, such investigations are often isolated and limited in their attempts to summarize the broad areas of available research. There are some existing reviews on prevalence rates of bullying on the island of Ireland (e.g., Mc Guckin, 2013; O'Moore, 2013), which provide a platform for the current research. However, there has been renewed interest in recent years, perhaps as a result of high profile cases of cyberbullying incidences covered in the media. As such, we determined that a systematic review of the literature and meta-analysis of the bullying and victimization prevalence rates are an important and necessary process in determining the current situation of traditional (face-to-face) bullying and cyberbullying for children and adolescents on the island of Ireland. The by-product of such a review will hopefully contribute to a future research agenda that targets particular areas that have been under-researched.

There are three central aims to the current systematic review and meta-analysis. First, we will synthesis the results on the prevalence rates of bullying and victimization and give details of the different types of bullying where possible according to different school levels and different moderators. Second, we will present the available evidence on the psychological impact of bullying (traditional and cyber) on our young people to date. Third, we will outline the intervention procedures that have been implemented in the context of Northern Ireland and the Republic. We will conclude by giving suggestions for future research agendas based on the gaps identified from the current literature search.

\section{Method}

\section{Search strategy}

The structure of this systematic review is based on the Preferred Reporting Items for Systematic Reviews and Meta-Analyses (PRISMA) guidelines (Moher, Liberati, Tetzlaff, Altman, \& The PRISMA Group, 2009; see Table S1). We conducted one literature search for cross-sectional and longitudinal studies of traditional bullying and cyberbullying behaviours (perpetrators, victims, or both) published between January 1997 and April 2016. The following search terms were used: bully* OR bulli* OR victim*, viole* OR aggress* OR harass* OR fight* OR antisocial* OR delinquen* OR cyber OR online* OR electronic OR virtual OR internet OR net OR web OR chat OR social net* AND ir*. These 
search terms were decided on after an initial search of the literature and reading in the area. We searched four electronic databases: PsycArticles, ERIC, PsycInfo, and Education Research Complete. These databases were chosen because they were representative of the international literature on the specific but related disciplines of psychology and education. We also searched the Department of Education's websites in both the North and Republic of Ireland and hand-searched the publications of known experts in the field. These areas were believed to be the most relevant to the area of bullying and the most common domains in which literature relevant to bullying is published.

\section{Inclusion and exclusion criteria}

The overall systematic literature search yielded 1,734 articles, 229 of which were duplicates. In order to be included in the analysis, the study had to meet several criteria. First, the study had to include a measure of either bullying or cyberbullying that was directly relevant to child and/or adolescent populations (4-18 years). Studies that assessed this age range in schools or other settings were included; however, the study had to include students themselves and not a third party (e.g., teacher) reporting on their behalf. Second, the studies that were included in the meta-analysis (first aim) were required to be quantitative and should report (or provide if contacted by the researchers) sufficient information (e.g., percentages and sample sizes). Finally, the studies needed to be published sources (dissertations and unpublished materials were not included). Studies were excluded for the following reasons: (1) It was a qualitative analysis; (2) it assessed other populations that were not solely based in Northern or the Republic of Ireland; (3) authors did not provide sufficient information when contacted for the metaanalysis; and (4) papers did not investigate a school-aged (4-18 years) population.

We reviewed the titles and abstracts of all articles found and excluded 1,466 on the criteria outlined above. The final sample consisted of 39 papers and is shown in Table 1.

\section{Data analysis}

To investigate our first aim (victimization and perpetration prevalence), we calculated a pooled percentage for each bullying type and for each school type (primary vs. postprimary) separately. The prevalence of bullying and victimization for each type of bullying across each school type was computed from the total sample and the specific sample size of bullies and victims.

Meta-analysis was conducted with the Comprehensive Meta-Analysis (CMA) software (Borenstein, Hedges, Higgins, \& Rothstein, 2005). Effect sizes are reported as pooled percentages with 95\% confidence intervals for each study. The difference (Cohen's $d$ ) compares the individual study's percentage to the overall percentage mean across studies at each bullying type and school type. A $d$ of .20 is a small, .50 medium, and .80 or more a large effect (Cohen, 1988). Effect sizes were analysed using the random-effects model, in which the error term is composed of variation originating from both within-study variability and between-study differences (Borenstein, Hedges, Higgins, \& Rothstein, 2009; Cooper \& Hedges, 1994).

The distribution of effect sizes was examined using tests of heterogeneity. Significant heterogeneity indicates that differences across effect sizes are likely due to sources other than sampling error, such as tools used, different answer codes, time frame, whether bullying definition was supplied or not, and gender. Categorical moderator tests were 


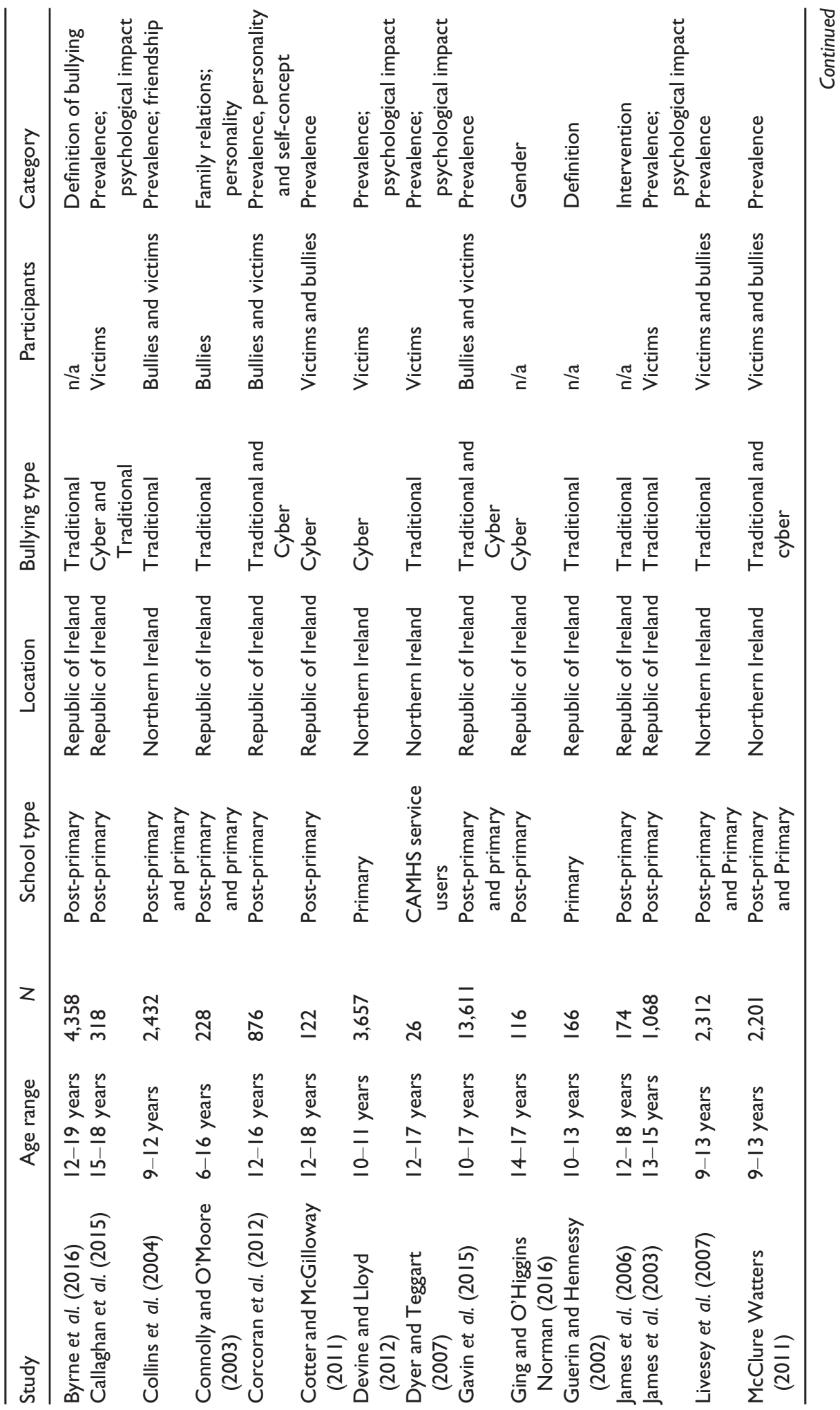




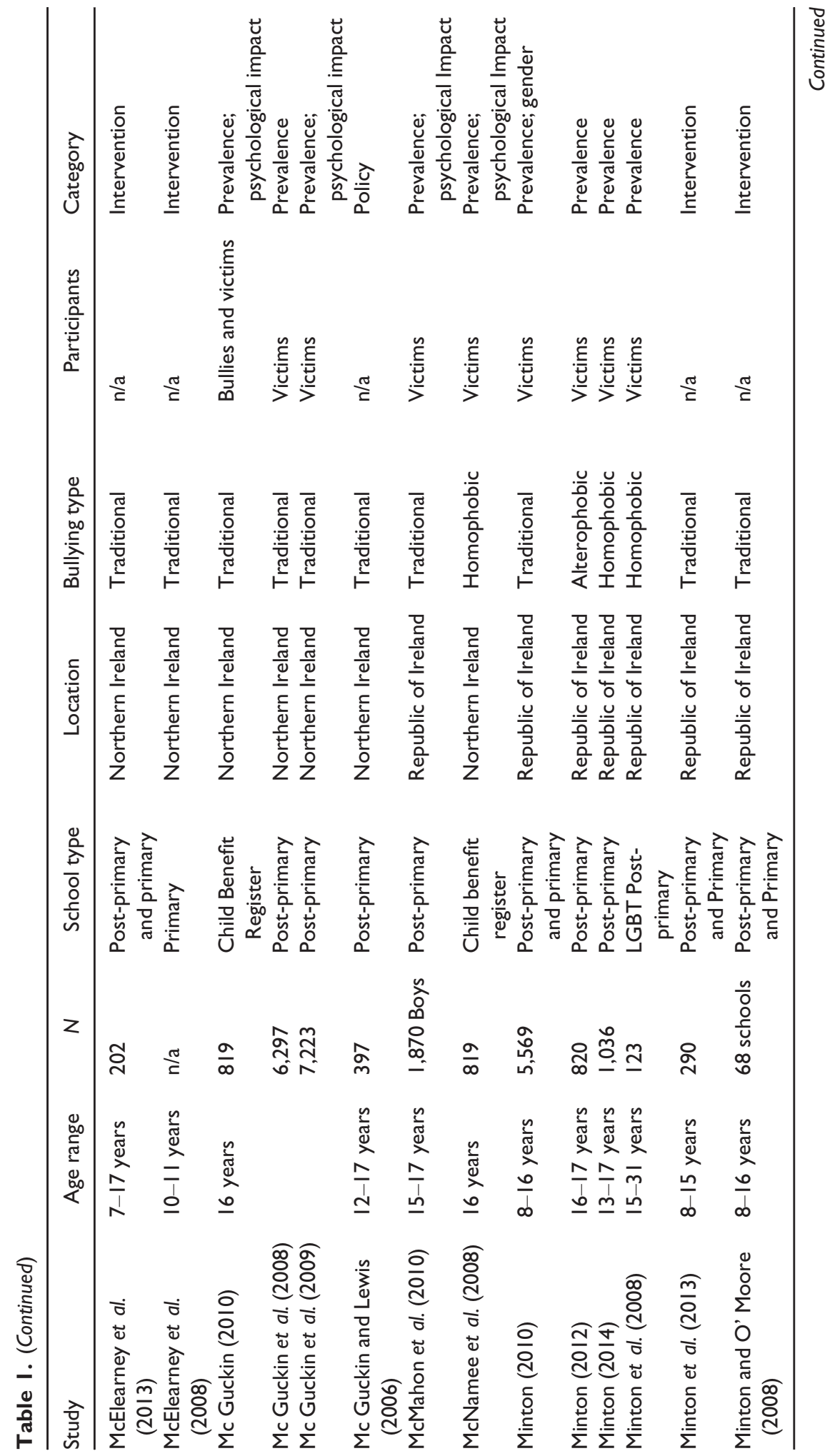




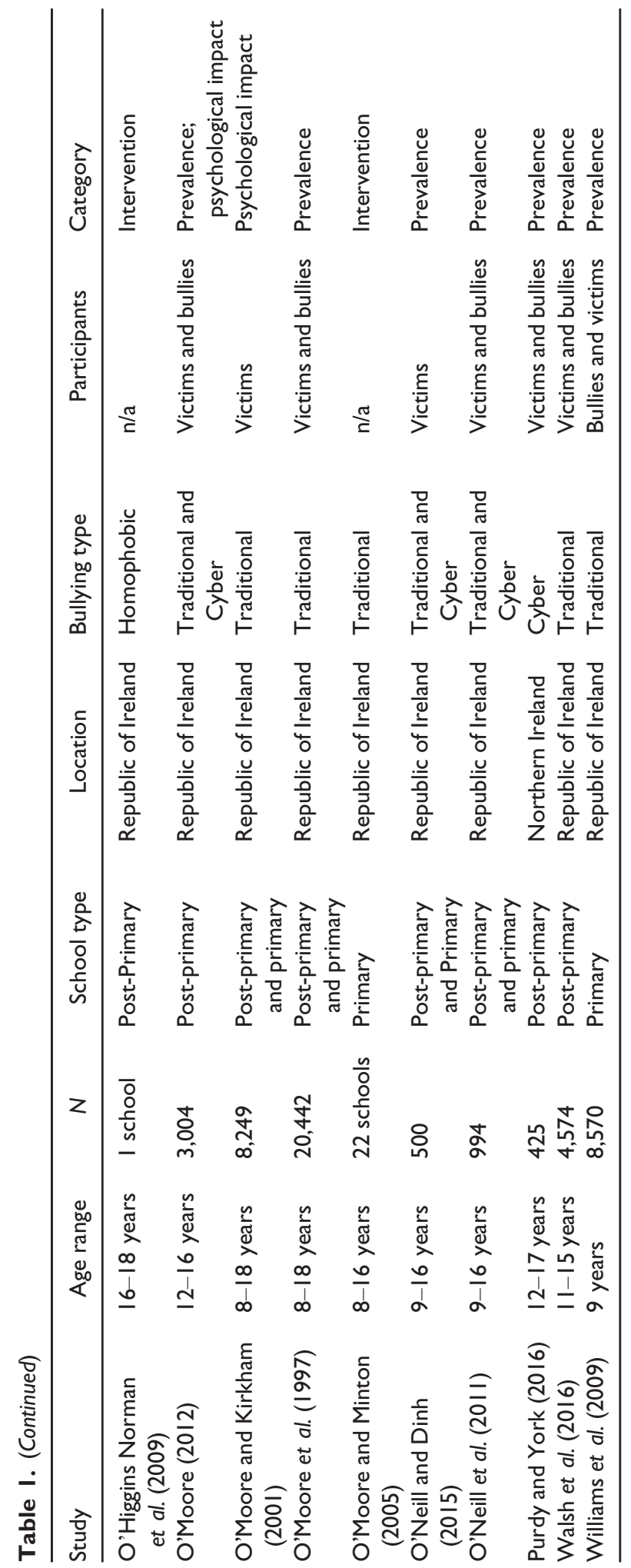


applied to test for between groups $Q\left(Q_{\mathrm{b}}\right)$. A significant value for $Q_{\mathrm{b}}$ indicates that the effect sizes are significantly different across different categories of the moderator variable.

We examined the potential for publication bias using two methods. The first is the Begg and Mazumdar (1994) rank correlation test (Kendall's tau b), which looks at bias according to study size. Hence, if small studies with controversial results were less likely to be published, the correlation between variance and effect size would be high. Conversely, lack of significant correlation can be seen as absence of publication bias. Secondly, we computed Rosenthal's fail-safe number (FSN; i.e., the number of studies that would be required to nullify the observed effect) for the combined effect size, separately for studies that looked at victimization and those which looked at bullying others to address the 'file drawer problem' (Rosenthal, 1991). A tolerance level around a fail-safe $N$ equal to 5 times the number of effect size $(k)$ plus 10 (' $5 k+10$ ' benchmark; Rosenthal, 1979) was calculated. Satisfactoriness is established if the fail-safe ratio exceeds Rosenthal's threshold at 1.00. As such, when the FSN consistently exceeds the $5 k+10$ benchmark, there is no need for additional research to establish the phenomenon.

For our second and third aims, a systematic review of the available literature is presented. The range in outcomes for psychological correlates (e.g., self-esteem, depression) was too broad to synthesis using CMA. Instead, they are described in detail below. There were few studies investigating interventions and they are also presented below.

\section{Results}

In general, the studies were divided into investigations of prevalence rates, psychological impacts, and interventions. Bullying prevalence was the most widely studied issue in the current set of studies (26 studies). Psychological impact was next with 10 papers directly relevant and then interventions (seven studies). Many papers reported findings of more than one of these categories (e.g., prevalence and impact), and some reported on other issues such as definitions, gender, and personality characteristics (8). The most common type of study was a cross-sectional analysis using a survey type research tool (e.g., the Olweus Bullying Questionnaire, OBQ), and the most common location was in a school setting. While we choose to focus on peer bullying in the child and adolescent years, it is worth noting that no investigations of sibling bullying were found in the search.

\section{Prevalence of bullying and victimization}

Most analyses involved investigations of school bullying, and as such, data collection predominately took place in schools across the island of Ireland. Several papers referred to bullying in general terms, not accounting for different types (e.g., physical or verbal), and most presented the students with definitions of what it encapsulated. The majority of studies focused on the adolescent years and gathered data in schools, with the exception of Dyer and Teggart (2007) who collected data in the Child and Adolescent Mental Health (CAMHS) service users in Northern Ireland. Details of these studies are provided in Table S2.

Prevalence rates varied greatly depending on the categorization implemented by the researchers. In order to get a pooled estimate of prevalence of traditional and cyber perpetration and victimization, we combined the studies in Northern Ireland and the Republic of Ireland (across primary and post-primary schools) and analysed them using 
CMA. The studies differed greatly in terms of (1) the methods used to collect data (e.g., OBQ vs. single questions); (2) the time frame participants were questioned about (ranging from 'ever' to 2 months previous); (3) the particular definition given, if at all; (4); the way in which involvement was categorized (answer scale: ranged from a simple 'yes' answer to 'every day'); (5) gender; and (6) whether the study supplied a definition of bullying or not. We therefore also included these as moderators to check their influence on prevalence.

\section{Victimization}

We calculated the overall pooled percentage for victimization across all studies for each bullying type and each school level (Table 2 and Table S3). Overall victimization rates for primary school (traditional and cyber combined) $(22.4 \% ; z=-7.88 ; 12$ studies; $p<.001)$ were significantly higher than the rate for post-primary (traditional, cyber, homophobic and alterophobic combined), 11.8\%; $z=-14.76 ; 28$ studies; $p<.001 ; Q_{\mathrm{b}}(\mathrm{df}: 1)=15.14$; $p<.001$, even when excluding homophobic and alterophobic studies, $Q_{\mathrm{b}}$ (df: $1)=13.64 ; p<.001$. It was also found that traditional victimization in primary schools (26.1\%) was significantly higher than post-primary, $12.4 \% ; Q_{\mathrm{b}}(\mathrm{df}: 1)=15.14 ; p<.001$. No significant differences for cyber victimization were found between primary schools (13.7\%) and post-primary schools (9.6\%).

When specific bullying types were investigated, traditional victimization (26.1\%; nine studies; $z=-7.45 ; p<.001)$ was significantly twice as high as cyber victimization (13.7\%; three studies; $z=-14.77 ; p<.001)$ in primary schools, $Q_{\mathrm{b}}(\mathrm{df:} 1)=18.16$; $p<.001$. Rates of cyber victimization ( $9.6 \%$; seven studies; $z=-10.40 ; p<.001$ ) were also less than traditional victimization $(12.4 \% ; 16$ studies; $z=-10.42 ; p<.001)$ at the post-primary level, but the differences were not significant, $Q_{\mathrm{b}}(\mathrm{df}: 1)=1.00 ; p=.316$.

The heterogeneity for the entire primary school sample, $Q(\mathrm{df}: 11)=3109 ; p<.001$; $I^{2}=99.65$, and post-primary sample, $Q(\mathrm{df}: 26)=6312 ; p<.001 ; I^{2}: 99.57$, was significant.

Moderator variables. Prevalence rates varied greatly and significantly when separated for the type of assessment used (see Table 2). In the primary sample, a pooled estimate of $23.9 \%$ was reported for traditional victimization for studies using the OBQ and $26.6 \%$ for OBQ modified, whereas a significantly higher rate was reported when specific questions were asked that required a simple Yes/No answer, $(40 \%), Q_{\mathrm{b}}(\mathrm{df}: 2)=19.49 ; p<.001$. Similarly, there were significant differences in prevalence rates for traditional victimization for coded responses, $Q_{\mathrm{b}}(\mathrm{df}: 5)=1041.57 ; p<.001$, even when studies used the same scale (standard five-point Likert scale) but included particular answers as being representative in victimization. A similar pattern was found for traditional bullying in postprimary pupils, $Q_{\mathrm{b}}(\mathrm{df}: 6)=68.22 ; p<.001$.

The time frame reported in these studies ranged from ' 2 months' to 'ever'. In general, this differed significantly across studies for both primary and post-primary pupils. For example, in primary schools, the larger the time frame students were asked about, the higher the percentage of traditional victimization, (2 months: $20.8 \%$; 3 months: $26.6 \%$; current school term: $30.7 \%$; 12 months: $40 \%$ ), $Q_{\mathrm{b}}$ (df: 3$)=12.63 ; p<.01$. In terms of gender, there was a significant effect for cyber victimization in primary schools; however, this was based on a group with one study only (separate results for boys and girls), whereas boys (15\%) and mixed-gender groups (combined boys and girls; 15.5\%) had higher cyber victimization rates compared to girls alone, $(11 \%), Q_{\mathrm{b}}(\mathrm{df}: 2)=33.85$; 


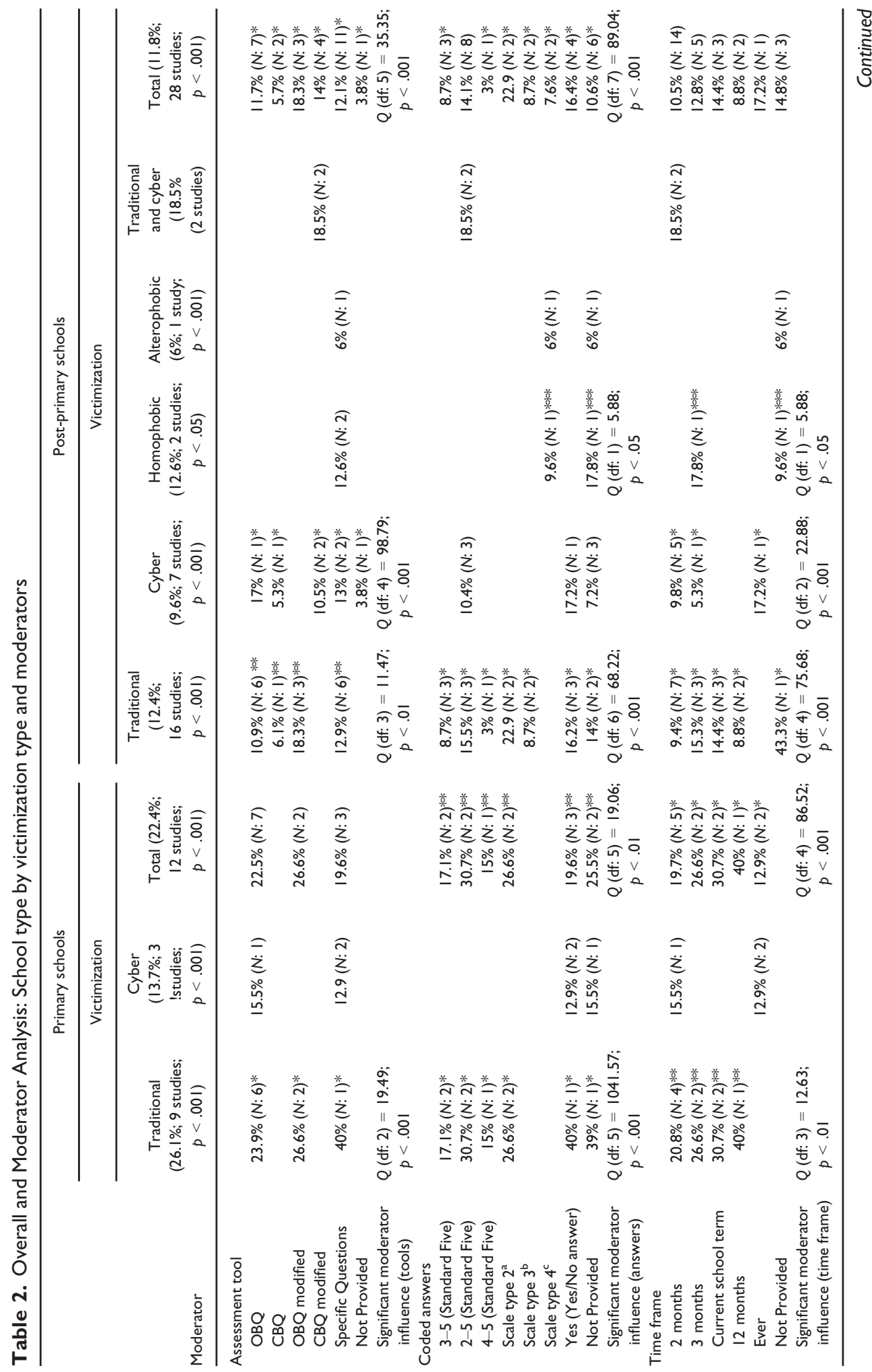




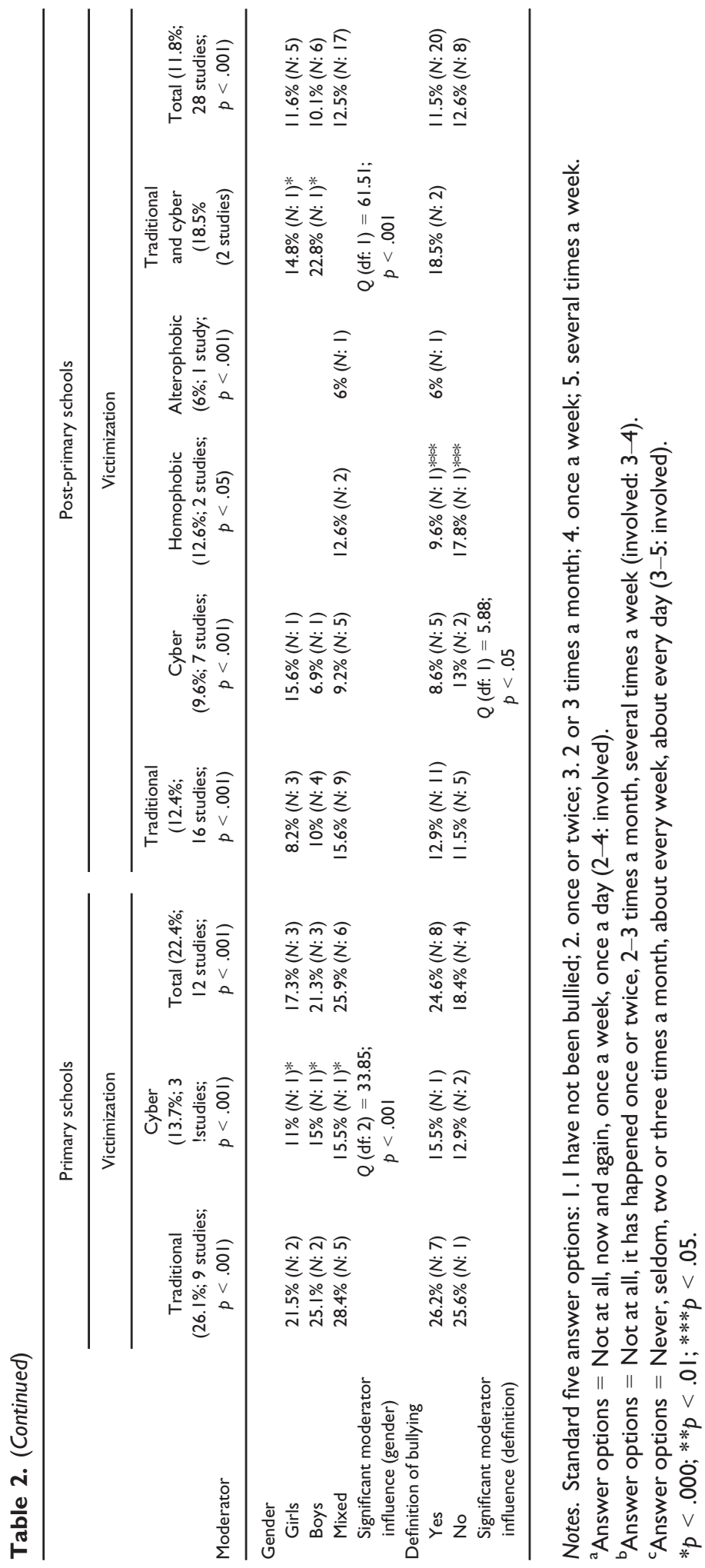


$p<.001$. There was no difference in victimization prevalence rates across the sample for whether a definition was included or not.

\section{Bullying perpetration}

We calculated the overall pooled percentage for bullying across all studies for each bullying type and each school level (Table 3 below and Table S4). Overall bullying rates (traditional and cyber combined) for primary school $(9.4 \% ; z=-8.7 ; 10$ studies; $p<.001)$ were not significantly higher than the rate for post-primary, $6.1 \% ; z=-15.88$; 22 studies; $p<.001 ; Q_{\mathrm{b}}(\mathrm{df}: 1)=2.16 ; p=.142$. Traditional bullying in primary $(10.1 \%$; $z=-7.74 ;$ nine studies; $p<.001)$ was higher than post-primary $(6.9 \% ; z=-11.38 ; 12$ studies; $p<.001$ ); however, this difference was not significant, $Q_{\mathrm{b}}$ (df: 1$)=1.28$; $p=.258$. Cyber perpetration rates were similar across both school types $(5.2 \%$ and $3.9 \%$, respectively).

When specific bullying types were investigated, traditional bullying (10.1\%; 9 studies; $z=-7.74 ; p<.001)$ was significantly twice as high as cyber $(5.2 \%$; one study; $z=-30.23 ; p<.001)$ in primary schools, $Q_{\mathrm{b}}(\mathrm{df:} 1)=5.76 ; p<.05$. Rates of cyber perpetration (3.9\%; six studies; $z=-16.24 ; p<.001$ ) were also significantly less than traditional victimization $(6.9 \% ; 12$ studies; $z=-11.38 ; p<.001)$ at post-primary, $Q_{\mathrm{b}}$ (df: 1) $=3.90 ; p<.05$.

The heterogeneity for the entire primary school sample, $Q(\mathrm{df}: 9)=5127 ; p<.001$; $I^{2}=99.82$ and post-primary sample, $Q(\mathrm{df}: 21)=4640.43 ; p<.001 ; I^{2}: 99.55$, was significant.

Moderator variables. Prevalence rates varied greatly and significantly when separated for the type of assessment used (see Table 3 ). In the primary sample, a pooled estimate of $11.3 \%$ was reported for traditional bullying for studies using the OBQ, 6.2\% for a modified version of OBQ, and $13 \%$ for the specific question scale, $Q_{\mathrm{b}}(\mathrm{df}: 2)=5.95 ; p=.05$. There was a significant difference for prevalence of traditional bullying in post-primary schools. For example, the rate of prevalence when the OBQ was used was $7.1 \%, 4.1 \%$ for the modified OBQ, and $4.9 \%$ for specific question scale, $Q_{\mathrm{b}}$ (df: 3$)=20.33 ; p<.001$. Similarly, there were significant differences in prevalence rates for traditional bullying for coded responses, $Q_{\mathrm{b}}(\mathrm{df:} 5)=228.87 ; p<.001$ in primary and in post-primary, $Q_{\mathrm{b}}$ (df: 6) $=85.72 ; p<.001$.

The larger the time frame students were asked about, the higher the percentage of overall bullying (traditional and cyber combined), $Q_{\mathrm{b}}(\mathrm{df}: 3)=11.53 ; p<.01$. The time frame was also significant for cyber perpetration in post-primary schools, $Q_{\mathrm{b}}$ (df: $2)=19.53 ; p<.001$. There was a significant effect for gender in post-primary for cyberbullying where boys had higher prevalence of cyberbullying compared to girls and mixed samples, $Q_{\mathrm{b}}(\mathrm{df}: 2)=7.41 ; p<.05$. The inclusion of a definition had a significant effect on cyber perpetration in the post-primary samples and studies who did not include a definition significantly reported higher cyberbullying rates compared to studies that did, $Q_{\mathrm{b}}(\mathrm{df:} 1)=7.29 ; p<.01$.

\section{Publication bias}

The Begg and Mazumdar rank correlation test (correlation between study size and effect size) suggests no evidence for publication bias for studies that investigated victimization 


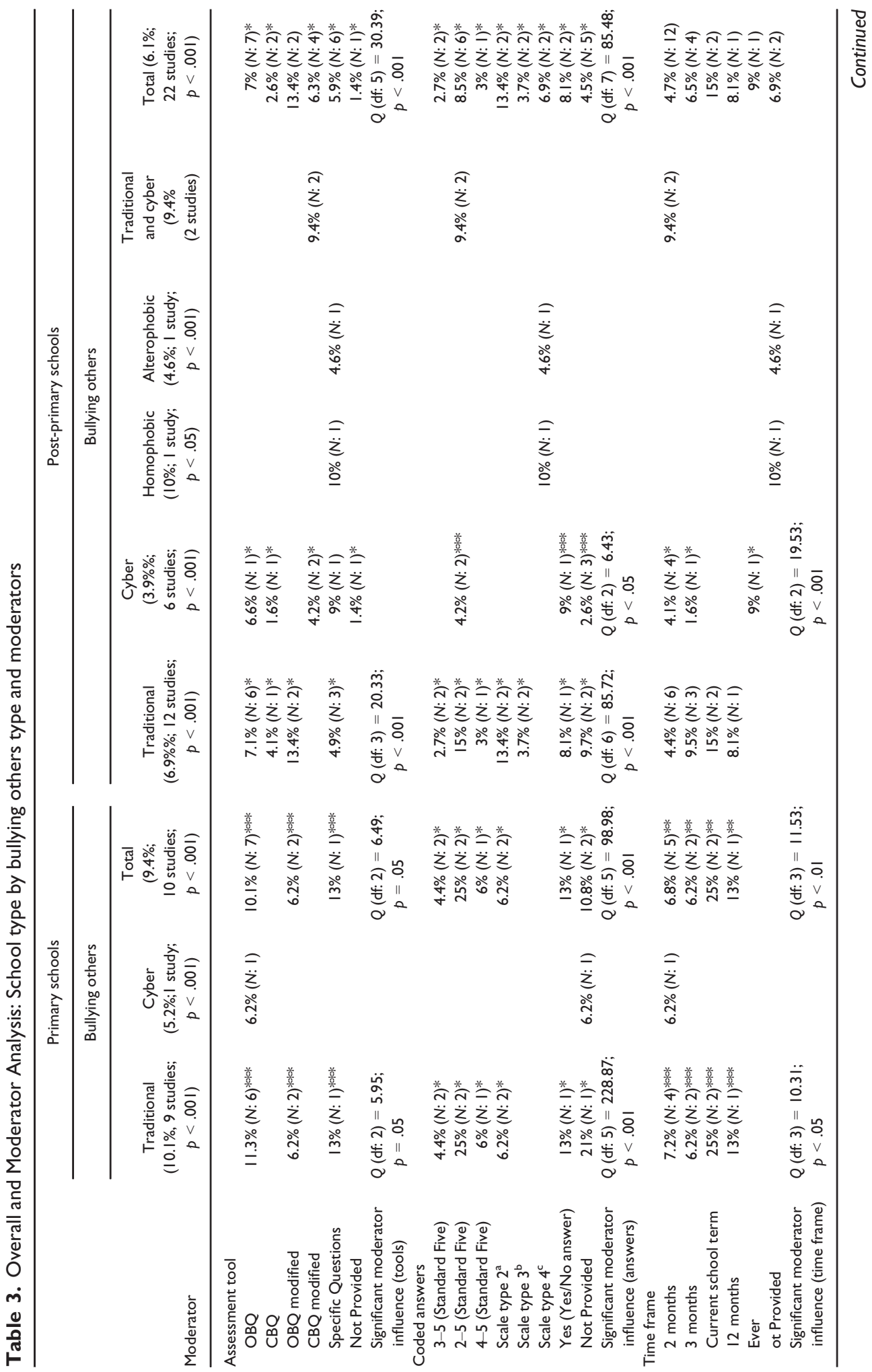




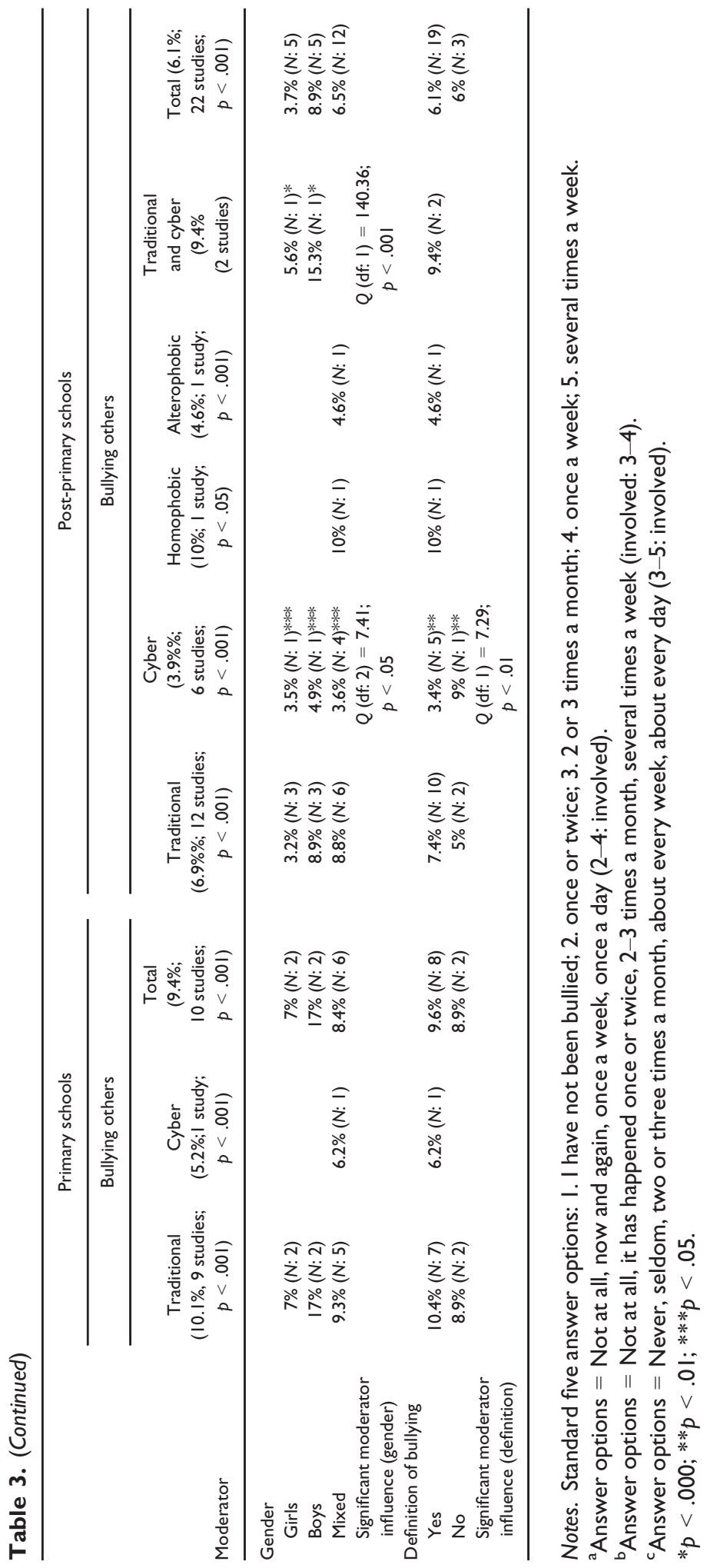


and bullying others. A fail-safe $N$ and the ' $5 k+10$ ' benchmark were calculated. For victims, the fail-safe $N$ was 38,939, which exceeded the benchmark $(5 k+10=210)$ suggesting no evidence of publication bias. For bullies, the fail-safe $N$ was 372,081, which also exceeded the benchmark $(5 k+10=170)$ suggesting no evidence of publication bias.

\section{Psychological correlates}

A range of psychological correlates was reported across the studies but in general they were related to self-esteem, life satisfaction, psychological well-being, and mental health. However, other factors like friendship and family relations were also investigated $(N=10)$.

In one of the earliest studies, O'Moore and Kirkham (2001) found that primary and post-primary victims of bullying had significantly lower global self-esteem than their nonvictim peers. This self-esteem was lowest for children who reported being frequently victimized (once a week and once a day). This study also found that pure victims had significantly higher global self-esteem than victims who also bullied others (bully/ victims). Significantly lower self-esteem was also reported for participants who bullied others compared to neutrals and again, it was lowest for those who did so 'frequently'.

More recently, Callaghan, Kelly, and Molcho (2015) found that victimization of any type of bullying was associated with poorer health and lower life satisfaction among secondary school students. This effect was particularly strong in relation to traditional bullying and was stronger among girls compared to boys. Devine and Lloyd (2012) found similar results in their Northern Irish sample of primary students (10-11 years) who had significantly poorer psychological well-being than their peers when exposed to cyberbullying. Mc Guckin (2010) also found that there were significant associations between victimization and poorer psychological well-being for a sample of 16-year-olds in Northern Ireland.

Dyer and Teggart (2007) investigated the relationship between previous experiences of bullying and attendance at the CAMHS and found that $62.5 \%$ of the participants said that previous bullying experiences played a moderate to very important role in their attendance at the clinic. In addition, McMahon, Reulbach, Keeley, Perry, and Arensman (2010) found that boys who had been bullied at school were more anxious and depressed and had poorer self-esteem than those without a history of bullying victimization. In particular, they found that victimization was associated with increased thoughts of selfharm when compared to those without such histories. Furthermore, James, Sofroniou, and Lawlor (2003) reported that 38\% of their sample of secondary school students $(N=1,068)$ felt depressed and $21 \%$ expressed suicidal thoughts when exposed to bullying.

Several other psychological factors were investigated across the studies, mostly as secondary objectives to investigations of prevalence rates and/or interventions. For example, O'Moore (2012) found gender differences in the reactions of 12- to 16-year-olds to cyberbullying and found that girls were more likely to feel upset and frightened, while more boys expressed anger than girls. Ging and O'Higgins Norman (2016) also reported feelings of upset after online interactions for 53\% of their sample of adolescent girls. In addition, Connolly and O'Moore (2003) investigated the personality of bullies and found that child bullies exhibited greater emotional inhibition and attributed significantly more negative statements to themselves than children who did not bully others. Friendship seemed to be a resilience factor buffering against victimization. Collins, McAleavy, and 
Adamson (2004) found a greater likelihood for pupils with fewer friends to be harassed by peers, with a greater percentage reporting more frequent forms of bullying than pupils with a larger number of friends.

\section{Interventions}

Intervention strategies were limited in this context $(N=7)$ and all appeared to target bullying in general, with little emphasis on the different types. A handful of studies conducted analyses of educational and whole-school antibullying initiatives and their impact on prevalence rates, and fewer still looked at psychological or individualized interventions (Table 4).

O'Moore and Minton (2005) reported an antibullying intervention that resulted in significant reductions of victimization over the course of 1 year, while Minton and $\mathrm{O}^{\prime}$ Moore (2008) report findings from the Anti-Bullying Centre's anti-bullying programme (2004-2006) and found significant reductions in post-primary school children's reports of bullying in the previous 3 months and secondary school pupils' reports of bullying in the previous 5 days. In addition, Minton, O' Mahoney, and Conway-Walsh (2013) reported results from the Erris Anti-bullying Initiative (2009-2011) and found non-significant reductions in the frequency of involvement in bullying among primary school students.

James et al. (2006) reported on the cool-school antibullying programme, which was administered in one school. Students reported feelings of increased safety and decreased bullying after the intervention although no objective measure of bullying rates was implemented to investigate its impact. Similarly, O’Higgins Norman, Goldrick, and Harrison (2009) delivered a pilot programme aimed at reducing homophobic bullying in a co-educational post-primary school. The study gathered pre- and post-intervention levels of homophobia among students, and the results showed a marginal increase in knowledge and increased empathy among males after exposure to the intervention.

A more recent study conducted in Northern Ireland, by McElearney, Adamson, Shevlin, and Bunting (2013), investigated the utility of a counselling service over the course of one year in a mixture of 47 primary and secondary schools across Northern Ireland. Results revealed a significant decrease in scores on the Strengths and Difficulties Questionnaire for the students who attended the counselling sessions. In an earlier study, McElearney, Roosmale-Cocq, Scott, and Stephenson (2008) investigated a peer support programme in a primary school in Ireland but did not empirically evaluate its utility.

\section{Discussion}

The results presented here demonstrate the almost fickle nature of our prevalence rates across studies on the island of Ireland. It shows quite apparently that these can be influenced by a range of factors, which often vary from one study to the next. These include methods of data collection, the answer scales, whether the study included a definition of bullying or not, and time frame for each tool. Although we were able to establish a pooled estimate of prevalence rate, the moderator variables showed that these rates need to be interpreted with extreme caution. That said, the CMA analysis did allow us to deduce overall prevalence rates for victimization and perpetration for each school type, method of assessment, time frame, and answer scale. At the very least, this gives us a tentative figure, which we can draw general conclusions about Irish students (Republic 
Table 4. Overview of the studies investigating bullying interventions in schools

\begin{tabular}{|c|c|c|c|c|}
\hline Study & Target population & & Intervention elements & Outcome \\
\hline James et al. (2006) & Whole school & $\begin{array}{l}(1) \\
(2) \\
(3)\end{array}$ & $\begin{array}{l}\text { Students faith in teachers } \\
\text { Teacher's ability to deal with } \\
\text { bullying } \\
\text { Student's willingness and } \\
\text { confidence in speaking to } \\
\text { teachers } \\
\text { Feelings of safety at school } \\
\text { Parent education }\end{array}$ & $\begin{array}{l}72 \% \text { of pupils felt } \\
\text { safer at school }\end{array}$ \\
\hline $\begin{array}{l}\text { McElearney et al. } \\
(2008)\end{array}$ & $\begin{array}{l}\text { Befriending peer } \\
\text { support } \\
\text { programme }\end{array}$ & $\begin{array}{l}\text { (I) } \\
(2)\end{array}$ & $\begin{array}{l}\text { Training children as peer } \\
\text { supporters } \\
\text { Training in: (a) setting ground } \\
\text { rules; (b) team building; (c) } \\
\text { questioning skills; (d) } \\
\text { friendship }\end{array}$ & $\begin{array}{l}\text { No outcomes } \\
\text { measured }\end{array}$ \\
\hline $\begin{array}{l}\text { McElearney et al. } \\
(20 \mid 3)\end{array}$ & $\begin{array}{l}\text { Independent School } \\
\text { Counselling } \\
\text { service }\end{array}$ & $\begin{array}{l}(1) \\
(2)\end{array}$ & $\begin{array}{l}\text { Individually-based } \\
\text { Cognitive Behavioural Focus }\end{array}$ & $\begin{array}{l}\text { Significant decrease } \\
\text { in Strengths and } \\
\text { Difficulties } \\
\text { Questionnaire } \\
\text { scores across time }\end{array}$ \\
\hline Minton et al. (20I3) & Whole school & $\begin{array}{l}(1) \\
(2) \\
(3)\end{array}$ & $\begin{array}{l}\text { Training network of } \\
\text { professionals } \\
\text { Resource packs for teachers, } \\
\text { parents and students } \\
\text { Community development } \\
\text { emphasis }\end{array}$ & $\begin{array}{l}\text { Non-significant } \\
\text { reductions in } \\
\text { prevalence }\end{array}$ \\
\hline $\begin{array}{l}\text { Minton and } \\
\text { O' Moore (2008) }\end{array}$ & Whole school & $\begin{array}{l}(1) \\
(2) \\
(3) \\
(4)\end{array}$ & $\begin{array}{l}\text { Training network of } \\
\text { professionals } \\
\text { Teacher's resource pack } \\
\text { Parent's resource pack } \\
\text { Working with pupils }\end{array}$ & $\begin{array}{l}\text { Significant } \\
\text { reduction in } \\
\text { prevalence for } \\
\text { particular age } \\
\text { group and time } \\
\text { frame }\end{array}$ \\
\hline $\begin{array}{l}\text { O'Higgins Norman } \\
\text { et al. (2009) }\end{array}$ & Class-based & $\begin{array}{l}(1) \\
(2) \\
(3)\end{array}$ & $\begin{array}{l}\text { Nature and Morality } \\
\text { Rights of gay and lesbian } \\
\text { people } \\
\text { Church responsibilities to } \\
\text { Gay and Lesbian People }\end{array}$ & $\begin{array}{l}\text { General increase in } \\
\text { positive attitudes } \\
\text { to LGBT issues }\end{array}$ \\
\hline $\begin{array}{l}\text { O'Moore and } \\
\text { Minton (2005) }\end{array}$ & Whole school & $\begin{array}{l}(1) \\
(2) \\
(3) \\
(4)\end{array}$ & $\begin{array}{l}\text { Training network of } \\
\text { professionals } \\
\text { Teacher's resource pack } \\
\text { Parent's resource pack } \\
\text { Working with pupils }\end{array}$ & $\begin{array}{l}\text { Significant } \\
\text { reduction in } \\
\text { prevalence }\end{array}$ \\
\hline
\end{tabular}

and Northern Irish) and how they compare to others worldwide. We can also use this figure to determine differences across the school stages (primary and post-primary).

Prevalence of vicitmisation (in types combined) was $22.4 \%$ in primary school and $12.1 \%$ in post-primary school across the island of Ireland. This rate was lower for bullying perpetration in primary (9.4\%) and post-primary (6.1\%). Cyberbullying involvement appeared to be lower when compared to traditional bullying, a finding which has been 
reported elsewhere (e.g., Modecki, Minchin, Harbaugh, Guerra, \& Runions, 2014). The range of cyber victimization rates is within the worldwide average (10-40\%; see Kowalski, Giumetti, Schroedr, Lattanner, \& Hinshaw, 2014). In contrast, the range of cyberbullying perpetration appears smaller than international comparisons. Hinduja and Patchin (2009) reported that $9 \%$ of the sample of middle school students were cyber bullies, which is higher than our figure of 5.2\% (primary) and 3.9\% (post-primary). There have been some arguments in the literature that rates of involvement in cyberbullying are on the increase. This is an important factor to consider in the light of the current results, which reports only one recent paper on cyberbullying (e.g., Purdy \& York, 2016). The rapid developments in technology, as well as the increase in social networking sites, and mobile phone usage suggest that a new investigation of prevalence rates of cyberbullying in Ireland is well over due.

The obvious moderator and measurement issues are key methodological concerns for local and international investigations of bullying. Indeed, researchers often define bullying using the definition by Olweus (1991), but we need to consider the possibility that meaning could vary between research and applied settings, not to mention between the students' unique understandings. One Irish study by Byrne, Dooley, Fitzgerald, and Dolphin (2016) found that students defined bullying with alternative concepts of 'mean', affecting feelings, and having different forms/types. This study also highlighted the differences in experience as a factor in how it was defined. For example, older females and identified victims of bullying were more likely to consider the psychological impact. This highlights a very important issue for how we implement awareness campaigns in schools and suggests that we need to work on the relevance of research and its practical applications.

Moving forward, the most advantageous approach would be to work towards developing a more united and standardized approach to the investigation of bullying behaviour. For example, an appropriate time frame could be agreed for research purposes. Furthermore, standards, in terms of reporting methods and results (e.g., the inclusion or exclusion of a definition), should be encouraged for researchers reporting in this field. Indeed, without these basic guidelines, comparisons between Northern Ireland and the Republic of Ireland and, internationally, are near impossible.

While not included in this review, it is worth noting a small number of important studies that have looked specifically at antibullying policies and the impact on bullying when they were utilized in a school setting. For example, Corcoran and Mc Guckin (2014) administered questionnaires to members of the National Association of Principals and Deputy Principals and found that all respondents implemented antibullying policies in their respective schools. Furthermore, a recent content analysis of antibullying policies in Northern Ireland found that most schools included reference to physical, verbal, relational, and cyberbullying. However, only a minority mentioned racist, homophobic, sexual, adult/teacher-pupil bullying, or bullying related to disability or religion (Purdy \& Smith, 2016). Similar results were reported in an earlier study in the Republic of Ireland where $63 \%$ of secondary school teachers reported that their schools' antibullying policy was void of any reference to lesbian gay bisexual and transgener (LGBT) issues (O'Higgins Norman, 2008). A recent systematic review revealed that antibullying policies might be effective at reducing bullying if their content is based on research and theoretical evidence and if they are implemented with a high level of fidelity (Hall, 2017). However, more research is needed in this area to improve antibullying policies according to new research developments. 
To date, antibullying interventions have been predominately education based. While worthwhile and necessary, these studies present only a small portion of the problem and are lacking psychological analyses in terms of the impact on the mental health of our young people. For example, there were no studies which focused on other associated problems and/or externalizing behaviour such as conduct problems, truancy, or academic achievement, despite these being found to be significantly correlated to bullying in other countries (Hammig \& Jozkowski, 2013). In addition, the factors that make some students resilient to these stresses (e.g., caring friendships) are extremely important if we are to develop interventions that promote adaptive and proactive coping styles. Indeed, it is necessary to distinguish between educational and preventative measures (e.g., antibullying policies) and psychological interventions that are normally designed to provide support to victims based on their individual coping styles (Foody, Samara, \& Carlbring, 2015). Only then we will be able to account for and aid each child's individualized reaction to victimization.

There have been some noteworthy developments at governmental levels. The National Action Plan on bullying was developed in 2013 by the Department of Education and Skills in the Republic of Ireland with the goal of requiring schools to develop antibullying policies. Specific antibullying procedures for schools were published, which provided a definition of bullying, information on the impact and characteristics of the behaviour, and a template for schools to develop their own antibullying policies. More recently, the Northern Ireland assembly published an Act for addressing bullying in schools (NIA 71/11-16). This Act, which will likely come into place in September 2017, includes a definition of bullying and sets requirements for the Boards of Governors to record, report, and take preventative action against bullying in schools (Purdy, 2016). The utility and impact of this Act have yet to be determined, and more research and evaluations are necessary to see if legislating for bullying plays a preventative role (El Asam \& Samara, 2016; Foody, Samara, El Asam, Morsi, \& Khattab, 2017). Although these provide a positive step in the right direction, they are by no means exhaustive efforts in combating bullying and they clearly present challenges (e.g., resources and training for schools) that have yet to be worked out.

Indeed, policy development could come from looking at other countries where more extensive research has been conducted in the area. For example, in England and Northern Ireland it is a legal requirement to have an antibullying policy in schools (Purdy \& Smith, 2016; Smith \& Samara, 2003), the effectiveness of which has been studied over time (Smith, Mahdavi, et al., 2008; Smith, Smith, Osborn \& Samara, 2008; Smith et al., 2012). Samara and Smith (2008) investigated schools' use of these strategies in the United Kingdom, the effect of required legal policies and the antibullying pack provided by the government in 1996 and 2002. They found that most schools moved from having a bullying policy as part of a broader policy on behaviour and discipline, to having a separate antibullying policy.

Based on the analyses performed here, there is no evidence of publication bias either for study size or the number of studies published on bullying others and victimization in general. While some large-scale studies in Northern Ireland (e.g., Mc Guckin, Cummins, \& Lewis, 2008) and the Republic of Ireland (e.g., O'Moore, Kirkham, \& Smith, 1997) do exist, current and contemporary studies that take into account the changing face of bullying (e.g., specific forms such as homophobic) and between whom it happens (e.g., siblings; Wolke \& Samara, 2004) are lacking. So too are longitudinal studies which outline the effects of bullying overtime and in a manner that permits us to draw comparisons between different locations, subgroups, and gender. 
Of course, all of these investigations will only be considered appropriate if they make strong allowances for the methodological difficulties inherent in such studies. It is imperative that moving forward we consider the need for a shared and standard understanding of what bullying is in terms of both research and in applied settings (e.g., schools). Only then can we really compare between countries and cultures. The results presented here demonstrate the need for caution when investigating prevalence rates and show specifically that the tools, time frame, answer scale codes, and definitions all impact the final outcome. This is quite significant when one considers how easily we make cultural and international comparisons and, if anything, emphasizes the need for caution when interpreting these figures.

Moving forward, we also feel it imperative to be as specific as possible when reporting results from various cultures and countries globally. Indeed, any studies which have not specifically noted the uniqueness of Northern Ireland in this regard may be limited (see Mc Guckin, 2013). If there is room for variance in terms of prevention and intervention strategies, then we would also argue that there might be variance in prevalence and even types of bullying. Despite this, we also note the importance of comparing and contrasting bullying issues in Northern Ireland and the Republic of Ireland and feel that this is a worthwhile endeavour in the future. If anything, it may promote the use of standardized tools and measurement methods which are urgently needed.

\section{Funding sources}

Dr Foody is supported by the Irish Research Council of Ireland, and Dr Samara is supported by the Qatar National Research Fund (QNRF), a member of Qatar Foundation Doha, Qatar, National Priority Research Programs grant (NPRP 5-1134-3-240). We thank both funding bodies for their support in this project.

\section{References}

Begg, C. B., \& Mazumdar, M. (1994). Operating characteristics of a rank correlation test for publication bias. Biometrics, 50, 1088-1101. https://doi.org/10.2307/2533446

Borenstein, M., Hedges, L., Higgins, J., \& Rothstein, H. (2005). Comprehensive Meta-analysis (Version 2) [Computer Software]. Englewood, NJ: Biostat.

Borenstein, M., Hedges, L. V., Higgins, J. P. T., \& Rothstein, H. R. (2009). Introduction to metaanalysis. Chichester, UK: John Wiley.

Byrne, H., Dooley, B., Fitzgerald, A., \& Dolphin, L. (2016). Adolescents' definitions of bullying: The contribution of age, gender, and experience of bullying. European Journal of Psychology of Education, 31, 403-418. https://doi.org/10.1007/s10212-015-0271-8

Callaghan, M., Kelly, C., \& Molcho, M. (2015). Exploring traditional and cyberbullying among Irish adolescents. International Journal of Public Health, 60, 199-206. https://doi.org/10.1007/ s00038-014-0638-7

Cohen, J. (1988). Statistical power analyses for the behavioral sciences (2nd ed.). Hillsdale, NY: Erlbaum.

Collins, K., McAleavy, G., \& Adamson, G. (2004). Bullying in schools: A Northern Ireland study. Educational Research, 46(1), 55-71. https://doi.org/10.1080/0013188042000178827

Connolly, I., \& O'Moore, M. (2003). Personality and family relations of children who bully. Personality and Individual Differences, 35, 559-567. https://doi.org/10.1016/S0191-8869 (02)00218-0

Cooper, H., \& Hedges, L. (1994). The handbook of research synthesis. New York, NY: Russell Sage Foundation. 
Corcoran, L., Connolly, I., \& O'Moore, M. (2012). Cyberbullying in Irish schools: An investigation of personality and self-concept. The Irish Journal of Psychology, 33(4), 153-165. https://doi.org/ 10.1080/03033910.2012.677995

Corcoran, L., \& Mc Guckin, C. (2014). Addressing bullying problems in Irish schools and in cyberspace: A challenge for school management. Educational Research, 56(1), 48-64. https:// doi.org/10.1080/00131881.2013.874150

Cornell, D., Gregory, A., Huang, F., Xitao, F., \& Graesser, A. C. (2013). Perceived prevalence of teasing and bullying predicts high school dropout rates. Journal of Educational Psychology, 105(1), 138-149. https://doi.org/10.1037/a0030416

Cotter, P., \& McGilloway, S. (2011). Living in an 'electronic age': Cyberbullying among Irish adolescents. The Irish Journal of Education, 29, 45-56. https://doi.org/10.2307/41548683

Department of Education and Skills (2013). Action plan on bullying. Report of the anti-bullying working group to the Minister for Education and Skills. Dublin, Ireland: The Stationery Office. Retrieved from http://www.education.ie/servlet/blobservlet/tl_3rdlevel_accessreport.pdf

Devine, P., \& Lloyd, K. (2012). Internet use and psychological well-being among 10-year-old and 11year-old children. Child Care in Practice, 18, 5-22. https://doi.org/10.1080/13575279.2011. 621888

Dyer, K., \& Teggart, T. (2007). Bullying experiences of child and adolescent mental health serviceusers: A pilot survey. Child Care in Practice, 13, 351-365. https://doi.org/10.1080/ 13575270701488733

El Asam, A., \& Samara, M. (2016). Cyberbullying and the law: A review of psychological and legal challenges. Computers in Human Behaviour, 65, 127-141. https://doi.org/10.1016/j.chb. 2016.08.012

Foody, M., Samara, M., \& Carlbring, P. (2015). A review of cyberbullying and suggestions for online psychological therapy. Internet Interventions, 2, 235-242. https://doi.org/10.1016/j.invent. 2015.05.002

Foody, M., Samara, M., El Asam, A., Morsi, H., \& Khattab, A. (2017). A review of cyberbullying legislation in Qatar: Considerations for policy makers and educators. International Journal of Law and Psychiatry, 50, 45-51. https://doi.org/10.1016/j.ijlp.2016.10.013

Gavin, A., Keane, E., Callaghan, M., Molchol, M., Kelly, C., \& Nic Gabhaiin, S. (2015). The Irish bealth behaviour in school-aged children (HBSC) study 2014. Galway, Ireland: Health Promotion Research Centre, National University of Ireland.

Ging, D., \& O'Higgins Norman, J. (2016). Cyberbullying, conflict management or just messing? Teenage girls' understandings and experiences of gender, friendship, and conflict on Facebook in an Irish second-level school. Feminist Media Studies, 16(5), 1-17. https://doi.org/10.1080/ 14680777.2015 .1137959

Grigg, D. W. (2010). Cyber-aggression: Definition and concept of cyberbullying. Australian Journal of Guidance E Counselling, 20(2), 143-156. https://doi.org/10.1375/ajgc.20.2.143

Guerin, S., \& Hennessy, E. (2002). Pupils' definitions of bullying. European Journal of Psychology of Education, 17, 249-261. https://doi.org/10.1007/BF03173535

Hall, W. (2017). The effectiveness of policy interventions for school bullying: A systematic review. Journal of the Society for Social Work and Research, 8(1), 45-69. https://doi.org/10.1086/ 690565

Hammig, B., \& Jozkowski, K. (2013). Academic achievement, violent victimization, and bullying among U.S. high school students. Journal of Interpersonal Violence, 28, 1424-1436. https:// doi.org/10.1177/0886260512468247

Hinduja, S., \& Patchin, J. W. (2009). Bullying beyond the schoolyard: Preventing and responding to cyberbullying. Thousand Oaks, CA: Sage.

James, D. J., Lawlor, M., Flynn, A., Murphy, N., Courtney, P., \& Henry, B. (2006). One school's experience of engaging with a comprehensive anti-bullying programme in the Irish context: Adolescent and teacher perspectives. Pastoral Care in Education, 24(4), 39-48. https://doi. org/10.1111/j.1468-0122.2006.00389.x 
James, D. J., Sofroniou, N., \& Lawlor, M. (2003). The response of Irish adolescents to bullying. Irish Journal of Psychology, 24, 22-34.

Kowalski, R. M., Giumetti, G. W., Schroedr, A. N., Lattanner, M. R., \& Hinshaw, S. P. (2014). Bullying in the digital age: A critical review and meta-analysis of cyberbullying research among youth. Psychological Bulletin, 140(4), 1073-1137. https://doi.org/10.1037/a0035618

Livesey, G., McAlvery, G., Donegan, T., Duffy, J., O'Hagan, C., Adamson, G., \& White, R. (2007). The nature and extent of bullying in schools in the North of Ireland. Research report no 46. Bangor, Northern Ireland: Department of Education for Northern Ireland.

Mc Guckin, C. (2010). Experiences of school bullying, psychological well-being and stress in Northern Ireland: Findings from the young life and times survey, 2005. Research in Education, 83(1), 54-66.

Mc Guckin, C. (2013). Bullying in schools in Northern Ireland. In M. O'Moore \& P. Stevens (Eds.), Bullying in Irish education: Perspectives in research and practice (pp. 40-65). Cork, Ireland: Cork University Press.

Mc Guckin, C. M., Cummins, P. K., \& Lewis, C. A. (2008). Bully/victim problems in Northern Ireland's schools: Data from the 2000 "Young Persons' Behavior and Attitude Survey". Individual Differences Research, 6, 280-288.

Mc Guckin, C., Cummins, P. K., \& Lewis, C. A. (2009). Bully/victim problems in Northern Ireland's schools: Data from the 2003 Young Persons' Behavior and Attitude Survey. Adolescence, 44 (174), 347-358.

Mc Guckin, C., \& Lewis, C. A. (2006). Experiences of school bullying in northern Ireland: Data from the life and times survey. Adolescence, 41(162), 313-320.

McClure Watters (2011). The nature and extent of pupil bullying in schools in the north of Ireland. Research Report no 56. Bangor, Northern Ireland: Department of Education for Northern Ireland.

McElearney, A., Adamson, G., Shevlin, M., \& Bunting, B. (2013). Impact evaluation of a school-based counselling intervention in Northern Ireland: Is it effective for pupils who have been bullied? Child Care in Practice, 19(1), 4-22. https://doi.org/10.1080/13575279.2012.732557

McElearney, A., Roosmale-Cocq, S., Scott, J., \& Stephenson, P. (2008). Exploring the anti-bullying role of a befriending peer support programme: A case study within the primary school setting in Northern Ireland. Child Care in Practice, 14(2), 109-130. https://doi.org/10.1080/ 13575270701868694

McMahon, E. M., Reulbach, U., Keeley, H., Perry, I. J., \& Arensman, E. (2010). Bullying victimisation, self harm and associated factors in Irish adolescent boys. Social Science \& Medicine, 71, 13001307. https://doi.org/10.1016/j.socscimed.2010.06.034

McNamee, H., Lloyd, K., \& Schubotz, D. (2008). Same sex attraction, homophobic bullying and mental health of young people in Northern Ireland. Journal of Youth Studies, 11(1), 33-46. https://doi.org/10.1080/13676260701726222

Minton, S. J. (2010). Students' experiences of aggressive behaviour and bully/victim problems in Irish schools. Irish Educational Studies, 29(2), 131-152. https://doi.org/10.1080/033 23311003779035

Minton, S. J. (2012). Alterophobic bullying and pro-conformist aggression in a survey of upper secondary school students in Ireland. Journal of Aggression, Conflict and Peace Research, 4(2), 86-95. https://doi.org/10.1108/17596591211208292

Minton, J. S. (2014). Homophobic bullying: Evidence-based suggestions for intervention programmes. Journal of Aggression, Conflict and Peace Research, 6(3), 164-173. https://d oi.org/10.1108/jacpr-10-2013-0027

Minton, S. J., Dahl, T., O'Moore, A. M., \& Tuck, D. (2008). An exploratory survey of the experiences of homophobic bullying among lesbian, gay, bisexual and transgendered young people in Ireland. Irish Educational Studies, 27(2), 177-191. https://doi.org/10.1080/03323310 802021961

Minton, S. J., O' Mahoney, M., \& Conway-Walsh, R. (2013). A 'whole-school community development' approach to preventing and countering bullying: The Erris Anti-Bullying 
Initiative (2009-2011). Irish Educational Studies, 2, 233-249. https://doi.org/10.1080/ 03323315.2013 .784637

Minton, S. J., \& O' Moore, A. M. (2008). The effectiveness of a nationwide intervention programme to prevent and counter school bullying in Ireland. International Journal of Psychology \& Psychological Therapy, 8(1), 1-12.

Modecki, K. L., Minchin, J., Harbaugh, A. G., Guerra, N. G., \& Runions, K. C. (2014). Bullying prevalence across contexts: A meta-analysis measuring cyber and traditional bullying. Journal of Adolescent Health, 55, 602-611. https://doi.org/10.1016/j.jadohealth.2014.06.007

Moher, D., Liberati, A., Tetzlaff, J., Altman, D.G., \& PRISMA Group (2009). Preferred reporting items for systematic reviews and meta-analysis: The PRISMA statement. PLoS Medicine, 6:e1000097. https://doi.org/10.1136/bmj.b2535

O'Higgins Norman, J. (2008). Equality in the provision of social, personal and health education in the Republic of Ireland: The case of homophobic bullying? Pastoral Care in Education, 26(2), 6981. https://doi.org/10.1080/02643940802062568

O'Higgins Norman, J., Goldrick, M., \& Harrison, K. (2009). Pedagogy for diversity: Mediating between tradition and equality in schools. International Journal of Children's Spirituality, 14, 323-337. https://doi.org/10.1080/13644360903293549

Olweus, D. (1991). Bully/victim problems among schoolchildren: Basic facts and effects of a school based intervention program. In D. J. Pepler \& K. H. Rubin (Eds.), The development and treatment of childhood aggression (pp. 411-448). Hillsdale, MI: Erlbaum.

O'Moore, M. (2012). Cyber-bullying: The situation in Ireland. Pastoral Care in Education, 30, 209223. https://doi.org/10.1080/02643944.2012.688065

O'Moore, M. (2013). The prevalence of bullying and cyber-bullying in Irish schools. In M. O'Moore \& P. Stevens (Eds.), Bullying in Irish education: Perspectives in research and practice (pp. 4065). Cork, Ireland: Cork University Press.

O'Moore, A.M., \& Kirkham, C. (2001). Self-esteem and its relationship to bullying behaviour. Aggressive Behaviour, 27, 269-283.

O'Moore, A., Kirkham, C., \& Smith, M. (1997). Bullying behaviour in Irish schools: A nationwide study. The Irish Journal of Psychology, 18(2), 141-169. https://doi.org/10.1080/03033910. 1997.10558137

O'Moore, A. M., \& Minton, S. J. (2005). Evaluation of the effectiveness of an anti-bullying programme in primary schools. Aggressive Behavior, 31, 609-622. https://doi.org/10.1002/ab.20098

O'Neill, B., \& Dinh, T. (2015). Mobile technologies and the incidence of cyberbullying in seven european countries: Findings from Net Children Go Mobile. Societies, 5, 384-398. https://doi. org/10.3390/soc5020384

O'Neill, B., Grehan, S., \& Ólafsson, K. (2011). Risks and safety for children on the internet: The Ireland report. London, UK: EU Kids Online, LSE.

Purdy, N. (2016). The addressing bullying in schools (Northern Ireland) Bill and Act 2016. Education Law Journal, 17(3), 164-172.

Purdy, N., \& Smith, P. K. (2016). A content analysis of school anti-bullying policies in Northern Ireland. Educational Psychology in Practice: Theory, Research and Practice in Educational Psychology, 32(3), 281-295. https://doi.org/10.1080/02667363.2016.1161599

Purdy, N., \& York, L. (2016). A critical investigation of the nature and extent of cyberbullying in two post-primary schools in Northern Ireland. Pastoral Care in Education, 34(1), 13-23. https://d oi.org/10.1080/02643944.2015.1127989

Rosenthal, R. (1979). The file drawer problem and tolerance for null results. Psychological Bulletin, 86, 638-641. https://doi.org/10.1037/0033-2909.86.3.638

Rosenthal, R. (1991). Meta-analysis: A review. Psychosomatic Medicine, 53, 247-271.

Samara, M. M., \& Smith, P. K. (2008). How schools tackle bullying, and the use of whole school policies: Changes over the last decade. Educational Psychology, 28, 663-676. https://doi.org/ $10.1080 / 01443410802191910$

Smith, P. K. (2014). Understanding school bullying: Its nature and prevention strategies. London, UK: Sage. 
Smith, P. K., Kupferberg, A., Mora-Merchan, J. A., Samara, M., Bosley, S., \& Osborn, R. (2012). A content analysis of school anti-bullying policies: A follow-up after six years. Educational Psychology in Practice, 48, 47-70. https://doi.org/10.1080/02667363.2011.639344

Smith, P. K., Mahdavi, J., Carvalho, M., Fisher, S., Russel, S., \& Tippett, N. (2008). Cyberbullying: Its nature and impact in secondary school pupils. The Journal of Child Psychology and Psychiatry, 49, 376-385. https://doi.org/10.1111/j.1469-7610.2007.01846.x

Smith, P. K., \& Samara, M. (2003). Evaluation of the DfES anti-bullying pack (research brief RBX06-03). London, UK: Department for Education and Skills.

Smith, P. K., Smith, C., Osborn, R., \& Samara, M. (2008). A content analysis of school antibullying policies: A follow-up after six years. Educational Psychology in Practice, 24, 1-12. https://doi. org/10.1080/02667360701661165

Sticca, F., \& Perren, S. (2013). Is cyberbullying worse than traditional bullying? Examining the differential roles of medium, publicity, and anonymity for the perceived severity of bullying. Journal of Youth and Adolescence, 42, 739-750. https://doi.org/10.1007/s10964-012-9867-3

Walsh, S. D., De Clercq, B., Molcho, M., Harrel-Fisch, Y., Davison, C. M., Madsen, K. R., \& Steven, G. W. J. M. (2016). The relationship between immigrant school composition, classmate support and involvement in physical fighting and bullying among adolescent immigrants and nonimmigrants in 11 countries. Journal of Youth Adolescence, 45, 1-16. https://doi.org/10.1007/ s10964-015-0367-0

Williams, J., Greene, S., Doyle, E., Haris, E., Layte, R., McCoy, S., .. Thornton, M. (2009). Growing up in Ireland: The lives of 9 year olds. Dublin, Ireland: The Stationery Office.

Wolke, D., Copeland, W. E., Angold, A., \& Costello, E. J. (2013). Impact of bullying in childhood on adult health, crime, and social outcomes. Psychological Science, 24, 1958-1970. https://doi. org/10.1177/0956797613481608

Wolke, D., \& Samara, M. M. (2004). Bullied by siblings: Association with peer victimisation and behaviour problems in Israeli lower secondary school children. Journal of Child Psychology and Psychiatry, 45, 1015-1029. https://doi.org/10.1111/j.1469-7610.2004.t01-1-00293.x

Received I 4 June 20 16; revised version received 20 April 2017

\section{Supporting Information}

The following supporting information may be found in the online edition of the article:

Table S1. PRISMA 2009 Checklist for the current study.

Table S2. Overview of studies presenting prevalence rates.

Table S3. Meta-analysis plots for overall bullying victimisation.

Table S4. Meta-analysis plots for overall bullying perpetration 